\title{
NEUROLEPTANALGESIA WITH FENTANYL-DROPERIDOL: AN APPRECIATION BASED ON MORE THAN 1000 ANAESTHETICS FOR MAJOR SURGERY
}

\author{
Ubaid Aubry, m.D., Gaston Carugnan, M.D., Dens CharetTe, M.D., \\ Michaet Keeru-Szanto, M.D., and Jean-PaUd Lavalige, M.D. ${ }^{\circ}$
}

Neunoleptanalgesia (NLA) has been practiced in Europe since 1959, and today the largest personal series exceed 10,000 cases. ${ }^{1}$ The anaesthetic aims at providing psychomotor sedation while leaving cortical and homeostatic functions as intact as possible. ${ }^{2}$ At the present time this selective action is achieved by the use of two agents, droperidol and fentanyl. These are given intravenously and may be administered either independent of each other or as a standard mixture, usually supplementing nitrous-oxide anaesthesia.

First reports were cautiously received on this side of the Atlantic; ${ }^{3}$ American anaesthetists are as reluctant to employ anaesthetic "cocktails" as these are dear to the hearts of their European colleagues. It was shown subsequently, however, that NLA compares well with conventional anaesthetics in most situations and that it is decidedly superior to them in geriatric surgery, ${ }^{4}$ open-heart procedures, ${ }^{5}$ patient acceptance, ${ }^{6}$ and certain special surgical situations. ${ }^{7}$ In view of this mounting evidence a résumé of our technique and a review of the indications and contraindications for NLA, as seen after more than three years' experience with the drug, appear timely.

\section{Material aNd Methods}

Our patients came from the population of a 1000-bed teaching hospital. NLA was used sporadically on the gravest-risk individuals from late 1962 to mid-1963 and more extensively thereafter. 1000 anaesthetics had been administered by August 1964, and at the present writing (January 1966) we have accumulated well over 2500 cases. The series remains heavily weighted towards extensive operations and poor-risk patients. No patient was refused on account of his physical status.

Written consent was obtained from the first 150 patients receiving NLA: subsequently, the "new anaesthetic" was mentioned to the patients during preoperative rounds and their verbal consent was deemed sufficient.

We have administered NLA exclusively in form of the standard 50:1 mixture of droperidol and fentanyl, and used it only to supplement nitrous-oxide anaes-

\footnotetext{
- The authors are on the staff of Notre-Dame Hospital, Montréal. Drs. Charette and KeeriSzanto are members of the Departments of Surgery and Anaesthesia respectively, Universite de Montreal. The results were presented in part by the senior author (M. K-Sz.) at the Third World Congress of Anaesthesiologists, São Paulo, Brazil, September, 1964. The neuroleptanalgesic mixture (droperidol $2.5 \mathrm{mg}$. + fentanyl $0.05 \mathrm{mg}$. per ml., INNOvar) has been kindly furnished by Dr. E. C. Hessert of McNeil Laboratories Inc., Ft. Washington, Pa.
} 
thesia. Muscle relaxants were employed as required. This is a well-established technique; the differences between NLA and other supplements will be discussed in detail.

\section{Results}

Data from the first 1000 patients (preanaesthetic condition, course of anaesthesia, immediate and late recovery) were transferred to IBM punch-cards containing close to 100 bits of individual information. The information extracted from these cards is presented under the following headings:

1. Preanaesthetic condition: Table I.

2. Condition during surgery: Table II.

3. Immediate and late recovery: Table III.

4. Anaesthesia times, operations, drug-requirements and patient acceptance: Table IV.

5. Analysis of mortality: Table V.

TABLE I

Preanaesthetic Condrton, First 1000 NLA Patients

\begin{tabular}{lc}
\hline \hline Males & 433 \\
Females & 567 \\
Mean age (yrs.) & 46.8 \\
range & $2-87$ \\
Mean weight (lbs.) & 138.8 \\
range & $19-284$ \\
Anaesthetic risk & \\
1 & 570 \\
2 & 308 \\
3 & 77 \\
4 & 6 \\
E & 32 \\
reject & 7 \\
Abnormalities & 560 \\
none & 323 \\
1 & 100 \\
2 & 17 \\
3 & 281 \\
Cardiovascular & 167 \\
Respiratory & 100 \\
CNS & 22 \\
Allergy & \\
\hline
\end{tabular}

TABLE II

Peroperative Condition, First 1000 NLA Patients

\begin{tabular}{lc}
\hline Induction dose of NLA & $16.1 \pm 6.8 \mathrm{mg} .=12 \pm 5 \mathrm{mg} . / 100 \mathrm{lbs}$. \\
Induction time (min.) & $6.6 \pm 3.1$ \\
Maintenance dose of NLA (mg./100 lbs.) & $7.5 \pm 3$ \\
BP change > $20 \mathrm{~mm}$. Hg (pts.) & 310 \\
Muscle rigidity (pts.) & 51 \\
Laryngospasm, intubation or extubation (pts.) & 13 \\
Perspiration, any degree (pts.) & 82 \\
Estimated blood loss > 600 ml. (pts.) & 175 \\
Mean anaesthesia time (min.) & 157 \\
Range & $22-745$ \\
\hline
\end{tabular}


AUBRY et al.: NEUROLEPTANALGESIA WITH FENTANYL-DROPERIDOL

TABLE III

Postanaesthetic Condition, First 1000 NLA Patients

\begin{tabular}{lc}
\hline \hline Average time from end of surgery to talking (min.) & 10.5 \\
Received (pts) & 111 \\
narcotic antagonists & 167 \\
anti-curare drugs & 177 \\
respiratory assistance & 98 \\
Mean duration of respiratory assistance (min.) & 15 min. -48 hrs. \\
range & 112 \\
Nausea and/or vomiting at any time (pts.) & 4 \\
\hline
\end{tabular}

\section{Comment on Anaesthetic Technique}

The technique used in this series was essentially no different from other established methods for supplemented nitrous oxide anaesthesia. Nevertheless the following comments may be helpful.

\section{Premedication}

Conventional routine may be used. In this series promethazine-scopolamine yielded very satisfactory results, but no untoward effects were noted following meperidine-atropine premedication either. Diphenhydramine has been suggested as a particularly useful premedicant for NLA. ${ }^{8}$

\section{Induction}

Induction is slower with NLA than with thiopental (Table IV). Loss of consciousness occurs in five to six minutes if nitrous oxide is exhibited as soon as possible; it takes longer if only oxygen is given before intubation. In the types of cases with which we have dealt here, such delay was quite acceptable. Nevertheless, more recently we have limited ourselves to induction with pure NLA only in the gravest-risk patients and in those who promptly fall asleep after the injection of 10-15 mg. of the drug mixture. This dose will not provide full sleep in most patients: to these we administer a small dose (not more than $100 \mathrm{mg}$.) of thiopental. We then proceed with the intubation and add more NLA as needed during the preparation of the surgical field.

\section{Intubation}

Intubation was undertaken in the large majority of our patients because it was indicated by the nature of surgery. We could confirm the experience of others however $^{\theta}$ that the use of NLA without intubation requires a good deal of skill, owing principally to muscle rigidity and the resulting airway and ventilation problems. At the same time, intubation was uniformly smooth, even in patients who were otherwise too lightly anaesthetized. Severe laryngospasm was never encountered, and bucking only rarely; tachycardia and hypertension were the usual type of reaction to intubation under too light anaesthesia. Teaching intubation to new residents proved particularly easy, and manipulation of the tube during and after surgery was well tolerated, so well indeed that we learned to check routinely before incision whether or not the patients still reacted to their 


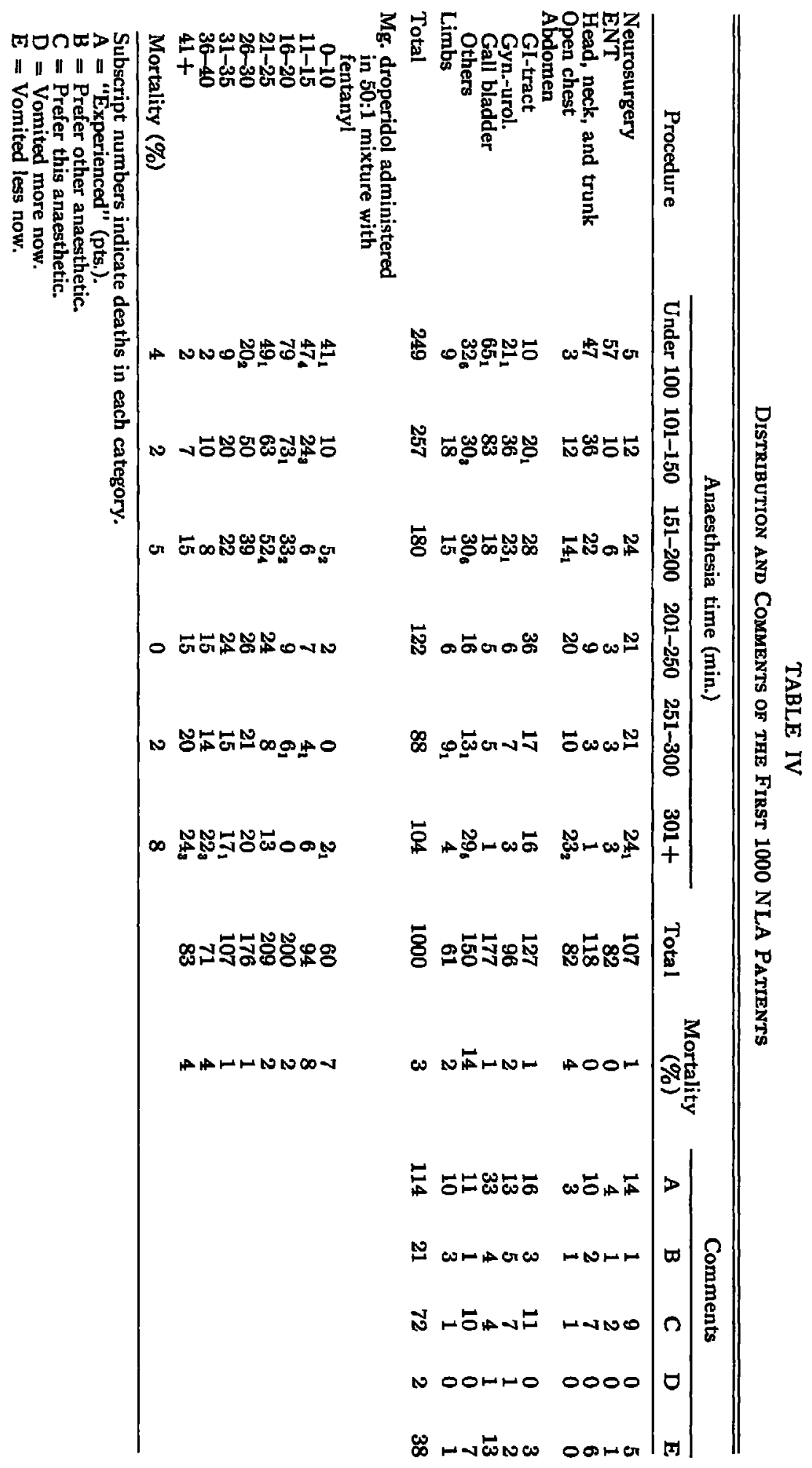


TABLE V

Mortality among the First 1000 NLA Patients

\begin{tabular}{ll}
\hline \hline Primary cause of death & Age/Died days postoperatively \\
\hline Pre-existing & \\
trauma & $57 / 0$ \\
debility & $85 / 11,83 / 2,81 / 1,73 / 2$ \\
shock & $63 / 3,60 / 1,83 / 3,74 / 2$ \\
infection & $59 / 14,46 / 10,62 / 7,73 / 3$ \\
tumour & $79 / 16,67 / 4,71 / 6,52 / 12$ \\
liver failure & $19 / 42,36 / 12$ \\
Complication & \\
coronary & $68 / 1,68 / 7,58 / 1$ \\
haemorrhage & $35 / 1,65 / 1,54 / 0$ \\
other circulatory & $63,26 / 3,28 / 3$ \\
respiratory & $64 / 5,66 / 5$ \\
\hline
\end{tabular}

names. If they did, anaesthesia was deepened in order to avoid reaction to the surgical stimulus.

\section{Maintenance}

Maintenance involved the use of nitrous oxide in all our cases. A semiclosed circuit was usually employed with the standard gas-flow of $2 \mathrm{~L} . \mathrm{N}_{2} \mathrm{O}+1 \mathrm{~L} . \mathrm{O}_{2}$ per minute. In virtually all our patients respiration was controlled, mechanically or manually. The anaesthesia was supplemented with increments of the droperidol-fentanyl mixture when it appeared insufficient, the usual dose being $2 \mathrm{mg}$. at a time. Our most reliable sign of anaesthetic insufficiency was a rising pulse rate, followed by blood-pressure changes, return of spontaneous respiration, grimacing, or reaction to the patient's spoken name. Muscle relaxants were given if the surgical field was unsatisfactory in spite of adequate anaesthesia, if there was diminished lung-compliance under the same circumstances, or (rarely) if we felt that the patient was taking too much NLA. Sweating, even dampness of the patient's forehead, was a rare event, and we could confirm once more the empirical finding that a dry skin during the entire operation virtually guarantees uneventful recovery from surgery. In most abdominal operations we found that by the end of surgery the patients had consumed about equal amounts of droperidol and d-tubocurare.

During anaesthesia of the proper depth most of our patients exhibited bradycardia in the vicinity of 60 to 72 beats per minute. Since the pulse was of excellent quality, we regarded this rate as evidence of efficient cardiac performance, and no remedial action was taken unless the pulse dropped below 50 beats per minute. In these rare instances a small dose of atropine provided relief. The incidence of haemodynamic upsets (Table II) was small, and such upsets were relatively benign considering the types of patients with whom we were dealing. Many of the recorded blood-pressure drops represented a return to normal levels from elevated preanaesthetic readings. In deciding upon treatment we were guided more by the quality of the pulse than by the blood pressure. Treatment was started by atropine and followed by more vigorous fluid therapy or digitalization as the case might be. Vasopressors were rarely employed: if a small dose of methedrine 
(5-10 mg. i.v.) was not effective, a norepinephrine drip or isopropyl-norepinephrine drip was installed, but this was required only a very few times and never as the result of anaesthesia.

\section{Immediate Recovery}

During the recovery period the patients slept when left to themselves but reacted to their spoken names and obeyed simple commands. Their respiration could be quite slow, sometimes as low as six inspirations per minute, yet deep enough to provide adequate alveolar ventilation. (This was concluded from blood-gas analysis carried out on a small number of patients who appeared so depressed as to give rise to concern.) Narcotic antagonists (Table III) would increase the respiratory rate, but in the absence of frank overdose they served more to calm the nursing personnel than to provide relief to the patients. Haemodynamic upsets were exceptional during this period; when they occurred they were due to incomplete blood-replacement during surgery. Nausea or vomiting in the recovery room were encountered in less than one per cent of our patients, in spite of the prevalence of abdominal surgery in this series. Some of our surgical colleagues have come to abandon the routine use of gastric suction altogether.

About 25 per cent of our patients arrived in the recovery room with endotracheal tubes still in place, and many of these (18\% among the first thousand patients-Table III) received respiratory assistance for varying periods. Far from considering this a drawback of the technique, we feel that making such assistance possible is one of its principal advantages. This point of view has been developed elsewhere."

\section{Late Recovery}

NLA differs from other anaesthetics principally in the low incidence of gastrointestinal complaints, even in patients who have vomited regularly after other anaesthetics administered on some previous occasion (Table IV). Our star performer in this respect was the OR-supervisor of another hospital, in whom NLA was the first of eighteen anaesthetics that was not followed by vomiting. This was undoubtedly the most important single factor to account for the quick acceptance of NLA by our patients. While most patients were amnesic of any respiratory assistance they might have received after surgery, those who recalled it described the experience as quite disagreeable. With increasing experience we have reduced these complaints, principally by better selection of subjects who would benefit from the procedure and by paying the closest attention to the comfort of these patients by reassurance and, if necessary, by the continued administration of NLA in subanaesthetic doses.

A complaint, rare but spectacular, appears to be specific to NLA: the occurrence of extrapyramidal movements. Characteristically these would set in 24 hours after uneventful recovery from anaesthesia and would not be accompanied by cyanosis or loss of consciousness. They upset the patients (and the families even more) but they are self-limiting and are easily controlled by atropine or by antiparkinsonain drugs. They occur most frequently in children or young adults; in our hospital with one exception they followed tonsillectomies or mastoid 
surgery-the reason for this preference has not been established. Their over-all incidence has been under one-half of one per cent.

\section{Comments on the Merts OF NLA}

The first question any responsible investigator must decide in studies of this type is whether or not there is a need for the new anaesthetic. Experience shows that new agents which offer only quantitative improvement over existing drugs will rarely achieve popularity, no matter how statistically significant these improvements may be. The observed difference in haemodynamic disturbances, postanaesthetic nausea, and ease of intubation favouring NLA over other anaesthetics now in common use fall, to our minds, in this category. We could also show, however, that NLA makes prolonged respiratory assistance possible for precisely those patients who need it most. The resulting statistically significant improvement in geriatric mortality ${ }^{4}$ amounts to a qualitative difference between NLA and other anaesthetic agents and techniques. If this claim is valid, it would behoove all anaesthetists to seriously consider an agent that offers better chances of survival to a small portion of their patients and a more pleasant recovery to many more.

There has been some controversy ${ }^{10}$ whether to administer droperidol and fentanyl as a mixture of constant proportions or to use the two drugs separately, in which case the bulk of droperidol would be administered during induction, and during the operation the patients would receive mostly (but not exclusively) the analgesic fentanyl. Since our experience is limited to use of the mixture, we cannot go beyond stating that (a) we have found it entirely satisfactory in our hands, and (b) our patients' drug-consumption compares favourably with that of patients who received the two agents separately. To these considerations one might add that much force has been lost from the argument that one should administer drugs as needed and not in standard mixtures, since it has been demonstrated ${ }^{11}$ that various painful stimuli are not processed in a uniform fashion by the brain and that the analgesic action of drugs depends to a significant degree upon the pain modality against which they are employed. Furthermore, if postanaesthetic respiratory assistance is to be more widely practised, a measure of altered consciousness during the recovery period as produced by continued administration of droperidol becomes a very desirable feature. Finally, the simplicity of administering the same mixture during induction and maintenance also has its virtue.

On the basis of our experience to date we submit the following indications for the use of NLA: geriatric surgery, patients with existing haemodynamic disturbances or in whom such disturbances are anticipated in the course of surgery; patients in whom splanchnic perfusion might be jeopardized during surgery by the placement of packs and retractors, and-most importantly-patients who might profit from respiratory assistance during recovery from anaesthesia.

NLA would not be our first choice in children under ten or in patients with a known tendency to convulsions or to extrapyramidal symptoms, although these contraindications are not absolute. We have ceased to use NLA in our ENT 
patients except for cancer surgery. We would administer the drug carefully to subjects who have recently received massive doses of narcotics or tranquilizers, and we do not feel that it is best suited for minor interventions. We consider its use contraindicated in outpatient surgery because its advantages are outweighed by the slight chance of extrapyramidal movements setting in outside the hospital. We have found that NLA inhibits the nystagmus produced by stimulation of the VIIIth nerve. Since this sign is an important landmark in labyrinth surgery, the drug cannot be used for this procedure. It is a very useful antiemetic and sedative for stapedectomies and fenestration procedures.

During the past ten years, barbiturates, steroids, eugenol derivatives, and gamma-butyrates have been put forward as intravenous anaesthetics. In addition, halogenated inhalation agents, inert gases, electricity, hyperventilation, sound waves, and hypnosis were also investigated as potential anaesthetics. The high failure-rate among the new products urges a measure of caution and humility before yet another compound is submitted to the profession. At the same time the very magnitude of the effort spent on the synthesis and investigation of new anaesthetics indicates that the ideal drug is yet to be found. We do not pretend that NLA is this panacea. We do feel, however, that it presents for a certain type of patient a better anaesthetic than the ones now available. The time and effort spent on familiarizing oneself with it return important dividends in patient satisfaction and improved survival rates.

\section{SUMMARY}

1. The three-year experience with neuroleptanalgesia in a large teaching hospital is reviewed, and the records of the first thousand such anaesthetics are analysed in detail. The use of this anaesthetic in the supplementation of nitrousoxide-relaxant anaesthesia is described.

2. In patients such as those studied, NLA appears to have certain quantitative advantages over other agents: better circulation during surgery, reduced incidence of postanaesthetic nausea and vomiting, and good patient acceptance. More significantly, the anaesthetic is qualitatively different from other agents in that it makes prolonged postanaesthetic respiratory assistance without tracheotomy feasible.

3. These characteristics amount to specific indication for NLA in certain patients, particularly when major surgery is contemplated. The indications, and some contraindications, are reviewed.

\section{RÉSUMÉ}

Bien qu'utilisée en Europe depuis 1959, la neuroleptanalgésie (NLA) a été employée en Amérique de façon assez sporadique. Les auteurs ont analysé en détail les résultats de leurs premiers mille cas. Cet agent a été employé avec le protoxyde d'azote et le curare comme adjuvant-la technique d'anesthésie y est décrite. 
La NLA semble avoir certains avantages sur les autres agents anesthésiques. Elle permet une meilleure homéostase durant la chirurgie et diminue l'incidence des nausées et vomissements. Cette méthode facilite le maintien de l'assistance respiratoire de façon prolongée en postopératoire, sans avoir recours à la trachéotomie. Nous avons trouvé ici un avantage qualitatif sur les autres agents anesthésiques.

A cause de tous ces facteurs, la NLA a ses indications bien particulières chez certains patients, surtout pour les cas de chirurgie majeure et les mauvais risques. Les indications et quelques contre-indications ont été résumées.

\section{REFERENCES}

1. Janssen, P. A. Personal communication.

2. Henschel, W. F. Principes et Technique de la Neuroleptanalgesie. Proc. XIIIème Congrès français d'anesthesiologie, Bordeaux, 1963.

3. Survey of Anesthesiology 1963-65. Comments by G. F. Marx (7/518), A. R. Hunter (8/352), L. R. Orkin (8/485), and G. M. Wyant (9/64).

4. Aubry, U.; Denis, R.; Kreri-Szanto, M.; \& Parent, M. Factors Affecting Survival of the Geriatric Patient after Major Surgery. Canad. Anaesth. Soc. J. 12: 510 (1965).

5. Corssen, G.; Chodoff, P.; Domino, E. F.; \& Karn, D. R. Neuroleptanalgesia and Anaesthesia for Open-Heart Surgery, Pharmacologic Rationale, and Clinical Experience. J. Thoracic Surg. 49: 901 (1965).

6. Capugnan, G.; Keeri-Szanto, M.; Lavallée, J. P.; \& LePage, C. Innovar: First Experiences with a New Intravenous Anaesthetic in a Teaching Hospital. Anesth. \& Analg. 43: 560 (1964).

7. Bnows, A. S. Neuroleptanalgesia for the Surgical Treatment of Parkinsonism. Anaesthesia 19: 70 (1964).

8. Foldes, F. F. Personal communication.

9. Holderness, M. D.; Chase, P. E.; \& Drupps, R. D. A Narcotic Analgesic and Butyrophenone with Nitrous Oxide for General Anesthesia. Anesthesiology 24: 336 (1963).

10. Dobkan, A. B. \& LEE, P. K. Y. Neuroleptanalgesics: I. Effect of Droperidol, Fentanyl, Innovar, Benzquinamide, and Pentazocaine on the Duration of Thiopental-Induced Sleep in Dogs. Canad. Anaesth. Soc. J. 12: 34 (1965).

11. Robson, J. C.; Davenport, H. T.; \& Sugryama, R. Differentiation of Two Types of Pain by Anesthetics. Anesthesiology 26: 31 (1965). 